\title{
HISTÓRIA DE MULHERES: BREVE COMENTÁRIO SOBRE O TERRITÓRIO E A IDENTIDADE DAS QUEBRADEIRAS DE COCO BABAÇU NO MARANHÃ̃ ${ }^{1}$.
}

\author{
Josoaldo Lima Rêgo ${ }^{2}$; Maristela de Paula Andrade ${ }^{3}$ \\ josoaldo@ig.com.br; saudadem@elo.com.br
}

\section{RESUMO}

A construção da identidade das quebradeiras de coco babaçu está marcada pelo significado do uso do território e por formas particulares de organização desse grupo camponês. Neste artigo procuramos expor algumas das características do processo de mobilização política das quebradeiras de coco babaçu na região do Médio Mearim, no Maranhão.

Palavras-chave: Quebradeiras de coco babaçu; território; identidade; Maranhão

\section{RESUMEN}

La construcción de la identidad de las quebradoras de coco babaçu está marcada por el significado del uso del territorio y por formas particulares de organización de ese grupo campesino. En este artículo buscamos exponer algunas de las características del proceso de movilización política de las quebradoras de coco babaçu en la región del Medio Mearim, en Maranhão.

Palabras clave: quebradoras de coco babaçu, territorio, identidad, Maranhão

A atividade de coleta e quebra do coco babaçu ${ }^{4}$, no Médio Mearim ${ }^{5}$, passou por várias mudanças, que corresponderam tanto a transformações de caráter produtivo e organizacional, próprios da movimentação das famílias das quebradeiras de coco, quanto a interesses de caráter comercial/econômico de órgãos governamentais e nãogovernamentais.

Já em 14 de março de 1957, através do decreto $n^{\circ} 41.150$ do governo federal, foi criado o Grupo de Estudos do Babaçu que, para Valverde (1957: 3), tinha a finalidade de apresentar, "fundamentalmente, sugestões para o desenvolvimento da produção de babaçu em curto prazo". 
Observa-se nisso, um destaque ao tipo de preocupação que o poder público (através do uso estratégico do saber) almejava com a tentativa de estudar e, para eles, "racionalizar" o extrativismo do babaçu:

Realmente, o babaçu [...] é uma palmeira que representa uma riqueza digna da tôda a atenção pelos poderes públicos, dadas as suas inúmeras utilidades. Dela são extraídos, hoje em dia, sobretudo o óleo empregado nas indústrias de comestível e de sabão, e a torta para a alimentação do gado. Poderão ser também obtidos por processo industriais diversos, a glicerina, um sucedâneo de chocolate, o pixe, o carvão ativado (para descorante), combustível (como lenha ou matéria-prima para coque ou gasogênio), plásticos, capachos e escôvas grosseiras (das fibras). A produção local utiliza as fôlhas e o caule do babaçu como material de construção das casas pobres, e o palmito para alimentação do gado, especialmente dos porcos, e também das pessoas (VALVERDE, 1957: 3).

Principalmente a partir dessa concepção, várias medidas governamentais terão como foco a condução de políticas voltadas à utilização/exploração não só dos frutos da palmeira de babaçu, mas também das áreas correspondentes às de ocorrência dos babaçuais, tal como os decretos 5.549 e 5.550 de março de 1975 que permitiam a empresas ligadas à implantação dos projetos de celulose e cana-de-açúcar no Maranhão derrubarem milhares de hectares de babaçu, como observam Almeida (1995) e May (1990).

Nesse contexto, com a contribuição do surgimento de alguns processos de mobilização política de entidades representativas dos camponeses, no início da década de 1950, o território maranhense vai passando por transformações no tocante à ação política dos grupos camponeses.

No ano de 1956, a partir da multiplicação destas Associações, foi criada uma entidade de representação a nível estadual denominada Associação dos Trabalhadores Agrícolas do Maranhão (ATAM). As maiores mobilizações envolviam os conflitos provocados pela "invasão das roças pelo gado" dos grandes proprietários e a regulamentação do preço dos aforamentos. Os camponeses nordestinos deslocados nos períodos de seca aumentavam a demanda de terra, o que possibilitava aos latifundiários a elevação do preço do foro e um maior poder de barganha nas negociações com os camponeses (ALMEIDA, 1995: 31).

$\mathrm{Na}$ década de 1970, essas referidas políticas territoriais governamentais de maior impacto na vida camponesa, podem ser caracterizadas pela efetivação de ações voltadas objetivamente para o incentivo fiscal de projetos agropecuários. A chamada "Lei Sarney”, por exemplo, na verdade a Lei Estadual de Terras № 2979, de 17 de julho de 1969, contribuiu muitíssimo para o avanço da pecuária no Maranhão, pois foi a legitimadora da distribuição de milhares de hectares de terras públicas a particulares, 
sob a alegação da existência de "terras devolutas". Nisso, a grilagem das terras, associada ao avanço da pecuária, levou as famílias camponesas a uma condição de submissão que culminaria em uma situação de conflito, evidenciando o problema da concentração de terras e da restrição de acesso aos babaçuais.

Na região do Médio Mearim fortes conflitos foram travados, principalmente na década de 1980, tendo como foco de resistência centenas de famílias camponesas que lutaram, e lutam, dentre alguns outros motivos, contra a submissão causada pela apropriação das terras por grandes proprietários. A redução brusca do estoque de terras disponível à agricultura camponesa e ao extrativismo fez surgir, além de um confronto direto com vaqueiros, capangas, milícias privadas a serviço daqueles proprietários e policiais, outras formas de relações econômicas, além de situações conflitantes no momento das práticas extrativistas.

O relato da situação de conflito em alguns povoados, como em Ludovico - no Município de Lago do Junco - revela muito dos problemas enfrentados por esses grupos camponeses do Estado do Maranhão no decorrer da segunda metade do século XX. Essas situações implicavam em casos que iriam desde os conflitos diretos, verdadeiras guerras, com muitas mortes inclusive, assim como formas diversas de privatização das terras e redução das áreas de plantio (nas áreas usadas para produção) que foram gradativamente sendo entregues a grandes proprietários para a produção da pecuária extensiva (PAULA ANDRADE e FIGUEIREDO, 2005); (PAULA ANDRADE, 2005).

Nesse panorama, surgiram algumas organizações e outras foram fortalecidas. Os Sindicatos de Trabalhadores Rurais (STRs), por exemplo, sofreram algumas transformações já que os trabalhadores tiveram maior atuação interna em seus órgãos de classe, por meio da oposição sindical, participando diretamente e tomando a frente em processo de mobilização e conflito. Foi assim, inclusive, que as mulheres passaram, também, a se associar ao Sindicato, já que antes somente se associavam os homens. A associação das mulheres, em muitos casos, deu-se em contextos de luta pela direção dos Sindicatos. Outras organizações foram criadas e tiveram como base a participação e direção das quebradeiras de coco babaçu (por exemplo, os clubes de mães, as CEBs e clubes de jovens, animados pela Igreja Católica antes dos anos 80), além das várias associações locais de povoados (“comunidades"): da Associação das Mulheres Trabalhadoras Rurais - Lago do Junco (AMTR); a Associação em Áreas de Assentamento do Estado do Maranhão (ASSEMA); Cooperativa dos Pequenos Produtores Agroextrativistas de Lago do Junco (COPPALJ); Cooperativa dos Pequenos 
Produtores Agroextrativistas de Esperantinópolis; Cooperativa de Pequenos Produtores de São Luís Gonzaga; Cooperativa de Pequenos Produtores Agroextrativistas de Lima Campos; e do Movimento Interestadual das Quebradeiras de Coco Babaçu (MIQCB). Além da articulação políticas com outras dezenas de entidades religiosas e representantes de Trabalhadores Rurais.

A ASSEMA, criada em maio de 1989, é uma entidade que surge com o intuito de desenvolver atividades de apoio à pequena produção local e às famílias produtoras, através, principalmente, de acompanhamento técnico-agrícola, de estabelecimento de créditos e de políticas específicas voltadas ao fortalecimento da produção.

Essa Associação aglutina várias outras entidades através de uma associação coletiva de cooperativas de pequenos produtores, de associações comunitárias de áreas de assentamento, de sindicatos de trabalhadores rurais e associações de mulheres trabalhadoras rurais, nos municípios de Lima Campos, São Luiz Gonzaga, Lago do Junco e Esperantinópolis, além de contar com sócios individuais, advindos dos povoados que compreendem a área de atuação da associação.

A implantação da COPPALJ (em abril de 1991), no município de Lago do Junco, insere-se no processo de transformação das formas de produção e comercialização dos produtos caracterizados como agroextrativistas, incluindo os oriundos do babaçu. Sobre a ASSEMA e a implantação da COPPALJ, Silva (2001: 250- 251) explica:

\footnotetext{
Essa associação procura sempre demarcar um espaço de luta, querendo, com isso, viabilizar uma alternativa de enfrentamento de uma realidade adversa às famílias que procuram sobreviver através do extrativismo e das culturas tradicionais (arroz, feijão, milho e mandioca). Diante dessa realidade, a ASSEMA, após explicar o significado de uma cooperativa e as regras básicas que as regem, implantou a Cooperativa dos Pequenos Produtores Agroextrativistas de Lago do Junco - COPPALJ, em 17 de abril de 1991. com esta ação visava possibilitar às famílias camponesas envolvidas no processo produtivo uma forma de viabilizar a comercialização dos produtos agroextrativistas.
}

Nesse caso, a transformação no processo produtivo da agricultura camponesa, construída sob a forma de novas maneiras de organização institucional e de associativismo e cooperação, possibilitou duas importantes situações: a criação das chamadas cantinas - espaços destinados à compra de amêndoas de babaçu e à troca de mercadorias (gêneros alimentícios) diretamente nos povoados; e sua administração pelas próprias famílias camponesas, sócias da cantina, eliminando a figura do "atravessador" do processo de comercialização da produção. 
A COPPALJ realiza a extração do óleo de babaçu, por meio de prensas instaladas em 1992, inicialmente em Lago dos Rodrigues, efetivando, assim, o beneficiamento do babaçu e contribuindo para o desenvolvimento de relações comerciais que passariam a caracterizar o escoamento da produção de babaçu na região, sem "atravessadores" e, consequentemente, atingindo um preço mais alto.

Por meio do Programa de Comercialização da ASSEMA, a produção de óleo de babaçu, que hoje já pode ser refinado, alcançou mercados internos e também o externo como no caso da comercialização de óleo com a Body Shop International - BSI, para a produção de cosméticos, realizada na Inglaterra e consumida em vários países.

Segundo Almeida (1995), estudando os dados de exportação do Maranhão em 1994, portanto ainda nos primeiros anos de funcionamento da Cooperativa, essa exportação de óleo babaçu feita pela COPPALJ correspondeu a 21 toneladas, perfazendo um valor de US\$ 38.304. Em 1999 foram US\$ 230.000 (MESQUITA, 2001).

Há, ainda, dentre as atividades e articulações relativas à organização da produção no Médio Mearim, a Fábrica de Papel Reciclado em Lago dos Rodrigues e a Fábrica de Sabonetes em Ludovico, que possibilitam a produção e comercialização de produtos, tais como: óleo vegetal, papel reciclado com fibras vegetais e tintura natural, e o sabonete, que tem como matéria-prima o próprio óleo.

O sistema de cantinas, que funciona em dezenas de povoados da região, é caracterizado pelo estabelecimento de redes de relações locais (SILVA, 2001) responsáveis pela manutenção de uma economia entre os produtores. A comercialização passa a incorporar essencialmente a lógica de produção local, em suas variantes ligadas aos aspectos da economia camponesa: as necessidades de consumo em equilíbrio como a capacidade de produção familiar (CHAYANOV, 1981).

Nota-se, em relação ao preço pago pela amêndoa de babaçu, um acréscimo significativo quando há comparação das compras realizadas pela cantina (abastecida de mercadorias para troca, pela COPPALJ) com o preço pago pelos "atravessadores" que trabalham na comercialização com outras empresas de beneficiamento de óleo vegetal. Do mesmo modo, percebe-se uma diferença entre os locais nos quais as famílias estão organizadas em cooperativas e onde há o sistema de cantinas - caso dos povoados de Ludovico, Centrinho do Acrísio, Centrinho de Aparecida - e onde não existe esse tipo de organização - caso dos povoados Santo Antônio dos Sardinhas, Nova Luz, Morada Nova e Fedegozo. Em Santo Antônio dos Sardinhas, por exemplo, o preço do quilo da 
amêndoa, em novembro de 2003, estava a $\mathrm{R} \$ 0,55$, enquanto na COPPALJ, nas cantinas, estava sendo comprado a $\mathrm{R} \$ 0,70$, portanto por $\mathrm{R} \$ 0,15$ a mais, podendo chegar a um valor bem maior, em função da distribuição das sobras entre os associados, ao final de cada ano.

As quebradeiras de coco babaçu, no Médio Mearim, têm construído, assim, nas últimas duas décadas, fortes instrumentos de intervenção política nas estruturas de poder local e nacional. As características do processo de mobilização política dessas mulheres e suas famílias, faz com que as entidades que elas integram sejam identificadas como instituições de luta e resistência contra as ações de grandes proprietários de terra e mesmo de instância de Governos. Essas lutas e toda a resistência têm sido evidenciadas, principalmente, por meio de "bandeiras de luta" levantadas em favor de práticas ambientais e econômicas específicas, assim como do reconhecimento de uma identidade - quebradeira de coco.

A AMTR, por exemplo, é outra entidade de representação política que aglutina um segmento das quebradeiras de coco, no Médio Mearim. Criada em um processo de mobilização política articulado com o surgimento de outras (ASSEMA; STRs e MIQCB), essa associação caracteriza-se por realizar um trabalho mais de base entre as quebradeiras de coco na região, e tem como área de abrangência e atuação os municípios de Lago do Junco e Lago dos Rodrigues. No depoimento de D. Ivete, presidente da AMTR, é possível identificar, como área de atuação política, os seguintes povoados - chamados por ela de comunidades: em Lago do Junco: Centro do Bertulino, Centrinho do Acrísio, Ludovico, São Manoel, Pau Santo, São Sebastião, Cajazeira e Aparecida; em Lago dos Rodrigues: Abreu, Três Poços, São João da Mata, Morada Nova, Centro dos Custódios e São Francisco. Para a direção da AMTR estes são povoados onde se encontram as fundadoras e associadas da entidade e, portanto, fazem parte da área de atuação da AMTR.

O MIQCB, por outro lado, foi criado em 1990 a partir das discussões realizadas no Grupo de Estudos das Quebradeiras de Coco Babaçu, em meados de 1989, e institucionalizado em 2002 (transformado em associação - Associação do Movimento Interestadual das Quebradeiras de Coco Babaçu - AMIQCB), constituindo-se em uma organização de mulheres camponesas que se aglutinam a partir de critérios de luta em defesa do ambiente, com a proposta de agroextrativismo do coco babaçu; de preservação e do livre acesso aos babaçuais, estabelecida em muitos casos a partir de lutas de caráter político-jurídico como no caso da construção de uma proposta de 
legislação específica - Lei Babaçu Livre; e por formas particulares de cooperação e associativismo; ao lado, ainda, de uma organização institucional própria que compreende os Estados do Maranhão, Piauí, Pará e Tocantins. O Movimento foi consolidado depois da realização de dois encontros (Encontro Interestadual de Quebradeiras de Coco Babaçu do Maranhão, Piauí, Tocantins e Pará) ocorridos em setembro de 1991 e outubro de 1993, respectivamente.

O processo de "libertação do babaçu", como chamam algumas quebradeiras, está entrelaçado com outras características dessa mobilização política, como a forte participação das mulheres (PAULA ANDRADE, 2005) e o discurso marcado pela necessidade de acesso à terra, aos recursos naturais e de afirmação de saberes locais na lógica de uso desses recursos. Um dos principais discursos reivindicatórios do Movimento, o de preservação da palmeira de babaçu, contextualiza-se com as discussões sobre a problemática ambiental contemporânea, o que pode ser observado, principalmente, nas atividades ligadas às práticas agroextrativistas das roças orgânicas.

A questão da necessidade de preservação dos babaçuais e a posição da mulher nesse processo de mobilização aparecem inclusive nas letras das músicas construídas e cantadas por elas:

Hei! Não derrube esta palmeira

Hei! Não devore os palmeirais

Tu já sabes que não podes derrubar

Precisamos preservar as riquezas naturais.

O coco é para nós grande riqueza

É obra da natureza

Ninguém vai dizer que não

Porque da palha só faz casa pra morar

Já é meio de ajudar a maior população

Se faz o óleo para temperar comida

É um dos meios de vida

Pra os fracos de condição

Reconhecemos o valor que o coco tem

A casca serve também para fazer o carvão

Com o óleo do coco as mulheres caprichosas

fazem comidas gostosas 
de uma boa estimação

Merece tanto seu valor classificado

que com o óleo apurado se faz o melhor sabão

Palha de coco serve pra fazer chapéu

da madeira faz papel

inda aduba nosso chão

Tela de coco também é aproveitado

Faz quibano o cercado pra poder plantar feijão

A massa serve para engordar os porcos

Tá pouco o valor do coco

precisa darem atenção

Para os pobres este coco é meio de vida

Pisa o coco Margarida e bota o leite no capão

(XOTE DAS QUEBRADEIRAS DE COCO: Arquivos da ASSEMA; Músicas Cantadas no II Encontro Interestadual das Quebradeiras de Coco Babaçu do Maranhão, Piauí, Tocantins e Pará, 1993)

\section{Considerações finas}

A defesa dos babaçuais, enquanto perspectiva de luta de caráter ambiental apresenta, no caso das quebradeiras de coco, no Médio Mearim, vertentes que perpassam conflitos travados com os pretensos proprietários, direta ou indiretamente, assim como intervenções de natureza política na construção de propostas de uso dos recursos naturais de forma dita sustentável - do modelo de agroextrativismo (as roças orgânicas) -, e propostas de legislação de proteção dos babaçuais contra as derrubadas.

Um dos âmbitos de disputa e conquista está na elaboração de uma proposta de legislação que regulariza o acesso livre aos babaçuais que estão "entre as cercas", ou seja, em “áreas privadas”. No Maranhão, a Lei já vigora nos municípios de Lago do Junco, Lago dos Rodrigues, Esperantinópolis e São Luís Gonzaga, existindo ainda Projetos de Lei tramitando nos municípios de Lima Campos e Imperatriz, além da existência da Lei Estadual no 4734 de 18 de junho de 1986, que proíbe a derrubada de palmeiras.

As quebradeiras de coco consideram, fortemente, a sua identidade ligada à preservação desse ambiente, como fator de vínculo que transcende, em alguns 
momentos, a relação puramente material e/ou econômica. As representações sobre a natureza são construídas a partir do universo cotidiano, seguindo, nesse aspecto, a critérios de classificação que remetem às estruturas de classificação que levam em consideração aspectos étnicos de diferenciação religiosa, lingüística, econômica e políticas (WEBER, 1997); (BARTH, 1998). Seguindo, de acordo com os critérios internos aos grupos camponeses, lógicas específicas de organização territorial, como observado nos estudos de Mourão Sá (1975) e de Paula Andrade (1999), realizados no Maranhão.

O estigma que marcava as famílias das quebradeiras de coco apresentava conforme se observa em alguns aspectos da produção intelectual sobre o tema da produção do babaçu e sobre o território maranhense - fortes características de determinismo. Andrade (1969: 74), por exemplo, caracteriza o que ele chama de "caboclo maranhense" como sendo "sem instrução, sem preocupação com outras terras e sem conhecimento de outros povos [isolado]", que "vive cotidianamente ao lado e à sombra das palmeiras, delas retirando o que pode, o que lhes é gratuitamente oferecido".

A partir do processo de mobilização política das quebradeiras de coco, o ambiente passa a ser incorporado como instrumento de luta (política) e entendido por meio das possibilidades de relações simbólicas e econômicas estabelecidas a partir de vínculos, dessas mulheres e das organizações que elas integram, com as palmeiras e com os babaçuais.

\section{Notas}

${ }^{1}$ Trabalho desenvolvido junto ao Grupo de Estudos Rurais e Urbanos-GERUR/UFMA, no âmbito da pesquisa intitulada História de Mulheres: quebradeiras de coco babaçu - identidade e gênero face às politicas econômicas e ambientais.

2 Estudante de Mestrado do Programa de Pós-Graduação em Geografia Humana da Faculdade de Filosofia, Letras e Ciências Humanas/USP, Laboratório de Geografia Agrária da USP; Grupo de Estudos Rurais e Urbanos -GERUR/UFMA

${ }^{3}$ Professora Doutora vinculada ao Programa de Pós-Graduação em Ciências Sociais da Universidade Federal do Maranhão e Coordenadora do GERUR.

${ }^{4} \mathrm{O}$ babaçu, segundo os dados do IBGE (BRASIL, 1984), tem uma área de ocorrência que abrange nove Estados do Brasil: Maranhão; Goiás; Piauí; Amazonas; Pará; Mato Grosso; Ceará; Minas Gerais e Bahia. "É encontrado de forma dispersa no sub-bosque da floresta amazônica [...]. Após a derrubada da mata, o babaçu passa a constituir uma das espécies que mais se desenvolve na capoeira e na mata secundária." (BRASIL, 1984). O Maranhão aparece nessas fontes como Estado de maior concentração desse vegetal, no entanto é difícil precisar a área de sua ocorrência, pois os dados oficiais são divergentes: Para o IBGE (BRASIL, 1984) são 9.457.500 hectares no Maranhão, correspondendo a 66,6\% dos babaçuais do País $(14,187.500$ ha); Para o MIC, citado por Almeida (1995), seriam 10.303.503 hectares, o que corresponderia a $71 \%$ da área total. Na carta de uso e cobertura vegetal do Maranhão, produto do Zoneamento Ecológico Econômico do Estado do Maranhão, a classificação se dá associada a um mosaico 
que "compreendem áreas de usos diversos, associados com pastagens, florestas abertas (em exploração e/ou explorada) com vegetação degradada e com presença de babaçu”. Nessa classificação citada, há ainda a seguinte distinção: "quando a presença dessa palmeira está em torno de $20 \%$ na área, utiliza-se o termo 'com babaçu' e, se em alta concentração, acima de 50\%, utiliza-se o termo 'babaçual'" (MARANHÃO, 2002, p. 22).

5 A ocupação das terras do Médio Mearim, no Maranhão, realizado por "nordestinos" (ANDRADE, 1969); (TROVÃO, 1989) - cearenses, em muitos casos - foi um processo que teve entre as suas características a forte influência de políticas territoriais governamentais do decorrer das décadas de 1950, 1960, 1970 e 1980.

\section{Referências}

ALMEIDA, Alfredo W. B. de. Quebradeiras de Coco - identidade e mobilização: legislação específica e fontes documentais e arquivísticas. São Luís, 1995.

ANDRADE, Manuel Correia. Paisagens e Problemas do Brasil. São Paulo: Brasiliense, 1969.

BARTH, Fredrik. Grupos étnicos e suas fronteiras. In: POUTIGNAT, Philippe, STREIFF-FENART, Jocelyne. Teorias da etnicidade. São Paulo: UNESP, 1998.

BRASIL. Fundação Instituto Brasileiro de Geografia e Estatística. Atlas do Maranhão. Rio de Janeiro: FIBGE, 1984.

CHAYANOV, Alexander. Sobre a teoria dos sistemas econômicos não capitalistas. In: SILVA, José G. SBIKE, Nerida. A Questão Agrária. São Paulo: Brasiliense, 1981.

MARANHÃO. Atlas do Maranhão. Gerência de Planejamento e Desenvolvimento Econômico, Laboratório de Geoprocessamento-UEMA. São Luís: GEPLAN, 2002.

MAY, Peter Herman. Palmeiras em chamas: transformações agrárias e justiça social na Zona do Babaçu. São Luís: EMAPA/FINEP/ Fundação Ford, 1990.

MESQUITA, Benjamin Alvino de. As relações de produção e o extrativismo do babaçu nos Estados do Maranhão, Piauí, Pará e Tocantins. In: ALMEIDA, Alfredo Wagner Berno de (org). Economia do babaçu: levantamento preliminar de dados. São Luís: MIQCB, 2001.

MOURÃO SÁ, Laís. O Pão da Terra: propriedade comunal e campesinato livre na Baixada Maranhense. (Dissertação de Mestrado apresentada ao programa de pós-graduação em Antropologia Social da UFRJ), 1975.

OLIVEIRA, Francisco de. Elegia para uma Re(li)gião: SUDENE, Nordeste, planejamento e conflito de classe. Rio de Janeiro: Paz e Terra, 1981.

PAULA ANDRADE, Maristela de. Terra de Índio: identidade étnica e conflito em terras de uso comum. São Paulo: UFMA, 1999.

PAULA ANDRADE, Maristela de. FIGUEIREDO, Luciene Dias. Na Lei e na Marra - a luta pelo Livre acesso aos babaçuais. Rio de Janeiro, Action Aid Brasil, Cd, 56p. 2005.

PAULA ANDRADE, Maristela de. Mutirões, Empates e Greves: divisão sexual do trabalho guerreiro entre famílias de quebradeiras de coco babaçu, no Brasil. In: Lusotopie. XII (1-2), 2005, Leiden/Boston. Brill Publishers, 2005.

SILVA, Miguel Henrique da. A organização agroextrativista: experiências de cooperativas em Viana, Lago do Junco e São Miguel do Tocantins. In: ALMEIDA, Alfredo Wagner Berno de (org). Economia do babaçu: levantamento preliminar de dados. São Luís: MIQCB, 2001.

TROVÃO, José Ribamar. Ilha latifundiária na Amazônia Maranhense; estudo da expansão da fronteira agrícola no Médio Vale do Pindaré: o caso de Santa Inês. São Luís, UFMA/PPPG, 1989. 
VALVERDE, Orlando. Geografia Agrária do Brasil. Rio de Janeiro: CBPE-INEP-MEC, 1964.

VALVERDE, Orlando. Geografia Econômica e Social do Babaçu no Meio Norte. In: Revista Brasileira de Geografia, IBGE, ano XIX, n. 4, out./dez. 1957, p. 381-416.

VIOLA, Andreu (comp.). Antropología del desarrollo: Teorías y estudios etnográficos en América Latina. Barcelona-Buenos Aires-México: Paidós, 2000.

WEBER, Max. Comunidades Étnicas. In: Economia y Sociedad: Esbozo de Sociología comprensiva. México: Fundo de Cultura Económica, 1997. 